\title{
A long-necked tanystropheid from the Middle Triassic Moenkopi Formation (Anisian) provides insights into the ecology and biogeography of tanystropheids
}

\author{
Kiersten K. Formoso, Sterling J. Nesbitt, Adam C. Pritchard, \\ Michelle R. Stocker, and William G. Parker
}

\begin{abstract}
Archosauromorphs are a diverse and successful group of reptiles that radiated into a series of groups around the time of the end-Permian extinction. One of these groups of archosauromorphs, tanystropheids, consists of diverse forms, and some of the largest members of the group possessed extremely elongated cervical vertebrae (greater than five times longer than tall), resulting in a hyperelongate neck. These derived tanystropheids have been found in Tethyan marine deposits of Pangaea. Four partial cervical vertebrae from a hyperelongate-necked tanystropheid from the Middle Triassic Moenkopi Formation of Arizona and New Mexico are described in this paper. These cervical vertebrae are assigned to Tanystropheidae, specifically the clade that includes the hyperelongate-necked Tanystropheus based on character states, which include an elongate centrum (length to height ratio of 6.2), the presence of epipophyses, and an elongate axial centrum. The Moenkopi tanystropheid elements were found in lower latitude fluvial sequences without any marine influence, corresponding to western Pangaea, whereas Tanystropheus-like tanystropheids are typically associated with marginal marine environments in middle to high latitudes of eastern Pangaea. These fossils suggest that hyperelongate-necked, Tanystropheus-like tanystropheids were perhaps behaviorally bound to general semi-aquatic environments, both marine and freshwater, due to their unique morphology. These fossils also greatly extend the biogeographic range of large tanystropheids and increase the anatomical diversity of tanystropheids known from North America demonstrating that the clade persisted in a wide variety of environments throughout the Triassic Period.
\end{abstract}

Kiersten K. Formoso. Department of Geosciences, Virginia Tech, Blacksburg, Virginia 24061; Department of Earth Sciences, University of Southern California, Los Angeles, California 90089, USA.

formoso@usc.edu

Sterling J. Nesbitt. Department of Geosciences, Virginia Tech, Blacksburg, Virginia 24061, USA.

sjn2104@vt.edu

Adam C. Pritchard. Department of Paleobiology, Smithsonian Institution, Washington D.C., 20013, USA.

pritchardac@si.edu

Formoso, Kiersten K., Nesbitt, Sterling J., Pritchard, Adam C., Stocker, Michelle R., and Parker, William G. 2019. A long-necked tanystropheid from the Middle Triassic Moenkopi Formation (Anisian) provides insights into the ecology and biogeography of tanystropheids. Palaeontologia Electronica 22.3.73. 1-15. https://doi.org/10.26879/988

palaeo-electronica.org/content/2019/2824-long-necked-moenkopi-tanystropheid

Copyright: November 2019 Society of Vertebrate Paleontology.

This is an open access article distributed under the terms of the Creative Commons Attribution License, which permits unrestricted use, distribution, and reproduction in any medium, provided the original author and source are credited.

creativecommons.org/licenses/by/4.0/creativecommons.org/licenses/by-nc-sa/4.0/ 
Michelle R. Stocker. Department of Geosciences, Virginia Tech, Blacksburg, Virginia 24061, USA. stockerm@vt.edu

William G. Parker. National Park Service, Petrified Forest National Park, Petrified Forest, Arizona 86028, USA.william_parker@nps.gov

Keywords: Tanystropheidae; Archosauromorpha; biogeography; paleoecology; Triassic

Submission: 5 April 2019. Acceptance: 4 November 2019.

\section{INTRODUCTION}

The end-Permian Extinction (252 Ma) was the largest-known extinction event in Earth history, and it paved the way for subsequent diversification of the surviving fauna, particularly Archosauromorpha (including dinosaurs, birds, crocodiles, their relatives, and a diversity of extinct groups) in the Mesozoic Era starting in the Triassic Period (Romer, 1956; Benton, 2003; Shen et al., 2011; Ezcurra and Butler, 2018). Within the first half of the Triassic, archosauromorphs were incredibly diverse, demonstrated high morphological disparity, and were widespread across Pangaea (Sahney and Benton, 2008; Foth et al., 2016; Ezcurra and Butler, 2018). However, our understanding of the early diversification, biogeographic patterns, and ecologies of early archosauromorphs from the Early and Middle Triassic is limited because the fossil record of many of these clades consists of highly fragmentary, isolated elements from earlydiverging members; more complete skeletons are typically only known from younger, highly disparate taxa (Gregory, 1945; Wild, 1973; Nosotti, 2007; Nesbitt et al., 2010).

Tanystropheids are a unique group of archosauromorph reptiles, which likely appeared in the Late Permian (based on inferred ghost lineages) and diversified within five million years after the end-Permian extinction (Dilkes, 1998; Reisz and Müller, 2004; Ezcurra, 2016; Pritchard and Nesbitt, 2017). Temporally, tanystropheids ranged from the Early Triassic (247 Ma) with Augustaburiania vatagini of modern-day Eastern Europe as the oldest known representative of the group (Sennikov, 2011), to the middle Norian with an unnamed tanystropheid from the Hayden Quarry of the Chinle Formation $(\sim 212 \mathrm{Ma})$ in New Mexico (Pritchard et al., 2015), and the Rhaetian with a tanystropheid from Italy (Wild, 1980b). All tanystropheids have some degree of neck elongation (e.g., Amotosaurus rotfeldensis, Langobardisaurus pandolfii, Macrocnemus bassanii, and Tanytrachelos ahynis) relative to other archosauromorph groups; however, some tanystropheids took neck elongation to the extreme (Olsen, 1979; Renesto, 1994; Fraser and Rieppel, 2006; Casey et al., 2007; Ezcurra, 2016). Tanystropheus longobardicus, the largest and best-known member of Tanystropheidae, is characterized by an incredibly long and slender neck-roughly twice the length of the trunk-achieved by a composition of 13 highlyelongate cervical vertebrae with low neural arches (Rieppel et al., 2010). The hyperelongate neck of Tanystropheus longobardicus was longer than the body and tail combined, and Tanystropheus-like tanystropheids have some of the longest proportional necks of all reptiles.

Tanystropheids geographically occur widely across Triassic Pangaea. The clade is primarily known from the mid-latitudes of eastern Pangaea, and fossils of these animals are predominantly known from modern-day Europe, China, the Middle East, and eastern North America, often associated with marine environments in these regions (Olsen, 1979; Wild, 1980b; Vickers-Rich et al., 1999; Casey et al., 2007; Borsuk-Białynicka and Evans, 2009; Sues and Fraser, 2010; Sennikov, 2011; Sues and Olsen, 2014). However, there is a growing body of evidence of a diversity of tanystropheids in Western Pangaea supported by the following finds: an incomplete Tanystropheus-like cervical vertebra from the Middle/Upper Triassic Economy Member of the Wolfville Formation of Nova Scotia, Tanytrachelos ahynis and similar taxa of Upper Triassic deposits of the eastern United States ranging from New Jersey and Pennsylvania to Virginia, tanystropheid elements from the Upper Triassic Chinle Formation of western North America, Late Triassic tanystropheid elements from the Cooper Canyon Formation of Texas, and Early Triassic tanystropheid elements from the Sanga do Cabral Formation of Brazil (Olsen, 1979; Casey et al., 2007; Sues and Fraser, 2010; Sues and Olsen, 2015; Pritchard et al., 2015; De Oliveira et al., 2018; Lessner et al., 2018). The widespread biogeographic occurrences of tanystropheids and their persistent temporal ranges suggest that 
tanystropheids were extremely widespread in terrestrial and marginal marine ecosystems. However, the group of Tanystropheus-like tanystropheids, characterized by their hyperelongate necks are previously unknown from the western-edge regions of Pangaea like the other smaller tanystropheids.

Based on their morphology, as well as the marine environments from which their fossils are known, Tanystropheus has been thought to be at least semi-aquatic with numerous interpretations of it being fully aquatic. A fully aquatic lifestyle was originally thought to have been able to support the unique morphology of Tanystropheus' highly elongate necks, which were likely quite stiff because of the elongate structure of the cervicals and overlapping cervical ribs (Wild, 1973; Tschanz, 1988; Nosotti, 2007). Based on limb proportions and tail structure, Renesto and Saller (2018) hypothesized that Tanystropheus lived a shore-dwelling, semiaquatic lifestyle using hind limb propulsion in water, but frequently spent time on land (Renesto and Saller, 2018). Previously, Renesto (2005) inferred a semi-aquatic lifestyle based on tail and limb structure in a well-preserved Tanystropheus specimen from Valle Serrata in Switzerland (Renesto, 2005). Paleohistology and taphonomy have also recently been used to support a semi-aquatic existence for Tanystropheus (Jaquier and Scheyer, 2017; Beardmore and Furrer, 2018). These recent studies support the prevailing notion that Tanystropheus had morphological constraints that restricted it to at least semi-, but not fully-aquatic lifestyles (e.g., Wild, 1973) in marine and marginal environments of the Tethys Sea.

A new occurrence of a Tanystropheus-like taxon from the Moenkopi Formation of New Mexico and Arizona, which was deposited on the far western portion of equatorial Pangaea during the Middle Triassic, is described in this paper. We identify this hyperelongate-necked taxon based on four partial cervical vertebrae that share a number of synapomorphies with tanystropheids, specifically the highly disparate Tanystropheus, and we show that this occurrence adds new biogeographic and ecological information for this clade of a broader western Pangaean range and freshwater occurrence, respectively.

\section{GEOLOGICAL SETTING}

The described vertebral elements were found in the Holbrook and Anton Chico members of the Moenkopi Formation in northeastern Arizona and north-central New Mexico, respectively (Morales,
1987; Schoch et al., 2010). The Moenkopi Formation, spanning the Early to Middle Triassic, extends throughout the southwestern United States in Utah, Arizona, New Mexico, Nevada, southeastern California, and Colorado.

The Holbrook and Anton Chico members are thought to be Middle Triassic (Anisian; 247-242 $\mathrm{Ma}$ ) in age, and both are correlative members with each other as determined by vertebrate fossil evidence (Lucas and Hunt, 1987; Schoch et al., 2010). These members were formed from continental deposits predominantly consisting of crossstratified reddish-brown sandstones and siltstones, trough-stratified litharenites, beds of conglomerates, and freshwater limestone indicating that these particular members have no marine influence (McKee, 1954; Lucas and Hunt, 1987; Morales, 1987; Lucas and Schoch, 2002).

The Moenkopi Formation preserves a diverse assemblage of vertebrates including temnospondyl amphibians, dicynodonts, early actinopterygians, sarcopterygian fishes, chondrichthyans, nonarchosauriform archosauromorphs, archosaurs, and other amniotes of undetermined affinities, as well as invertebrates including arthropods, mollusks, and annelid trace fossils, and plants (Welles, 1947; Hunt et al., 1993; Morales, 1987; Nesbitt, 2003; 2005).

The cervical vertebrae described here (NMMNH P-80482, NMMNH P-80483, and NMMNH P-80484) were found in the Anton Chico Member, just north of the Pecos River, east of the town of Anton Chico, New Mexico, in fluvial conglomerate beds.

Specimen DMNH 2018-05-0003 was recovered in the Holbrook Member in the Little Colorado River valley, just southeast of Woodruff, Arizona, also in fluvial conglomerate beds (Figure 1). Specific locality information is on file at the New Mexico Museum of Natural History and Science and the Perot Museum of Nature and Science, respectively.

\section{MATERIALS AND METHODS}

\section{Measuring Methods}

The Moenkopi tanystropheid cervicals were measured using EZ Cal digital calipers. Centrum length was measured between the ventral margins of the outer rims of the centrum articular surfaces, or to the end of the preserved centrum if the element was broken. Centrum articular surface height was taken as a dorsoventral measurement from 


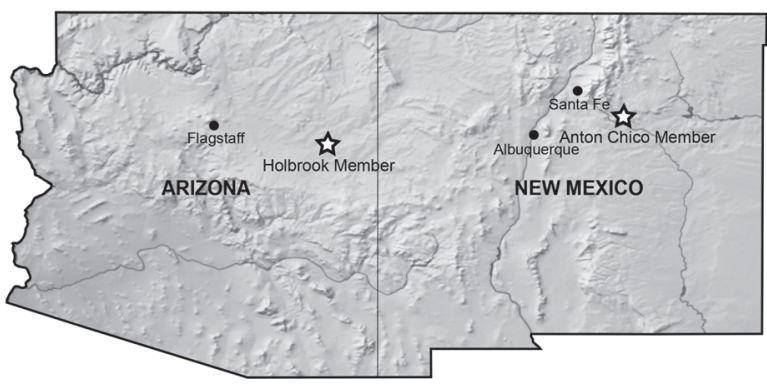

FIGURE 1. Holbrook and Anton Chico Member locations within the Moenkopi Formation of New Mexico and Arizona (National Geologic Map Database, USGS).

the outer rims of the anterior and/or posterior centrum articular surfaces.

\section{Preparation Methods}

Matrix was removed using a fine-tipped Microjack 1 (www.paleotools.com) air scribe under a Wild 9 dissection microscope to clear the matrix away from the cervical vertebrae. Broken pieces were glued using Loctite super glue. Fossils were prepared in the Virginia Tech Fossil Preparation Laboratory.

\section{Institutional Abbreviations}

DMNH, Perot Museum of Nature and Science, Dallas, TX, USA; NMMNH, New Mexico Museum of Natural History and Science, Albuquerque, NM, USA.

\section{SYSTEMATIC PALEONTOLOGY}

DIAPSIDA Osborn, 1903

SAURIA MacCartney, 1802 (sensu Gauthier, 1984) ARCHOSAUROMORPHA von Huene, 1946

(sensu Benton, 1985)

TANYSTROPHEIDAE Gervais, 1858

Figures 2-6

Referred specimens. An axis (DMNH 2018-050003 ) and three postaxial cervical vertebrae (NMMNH P-80482, NMMNH P-80843, NMMNH P80844). All specimens were found isolated.

Localities. Holbrook and Anton Chico members, correlative members, of the Moenkopi Formation of Arizona and New Mexico, U.S.A.

Age. Early, but not earliest Anisian Stage (244-242 Ma) of the Middle Triassic (Morales, 1987).

\section{DIAGNOSIS AND DESCRIPTION}

\section{Assignment to a Tanystropheus-like Tanystropheid Clade}

The referred cervical vertebrae are justified as tanystropheid cervicals based on the following character states. The neural spine of the axis is dorsoventrally short, being lower than the height of the axial centrum, which is a character state shared with Tanystropheus longobardicus, Amotosaurus rotfeldensis, and Macrocnemus bassanii (Ezcurra, 2016). The complete centrum of a postaxial cervical, NMMNH P-80482, exhibits a centrum length that is more than five times anteroposteriorly long than it is dorsoventrally tall, a character shared with the hyperelongate-necked tanystropheids (Pritchard et al., 2015; Ezcurra, 2016). The post-axial cervicals, NMMNH P-80482 through P-80483, have a flattened ventral surface of the anterior half of the centrum (excluding the keel) and this is also shared with tanystropheids (Pritchard et al., 2015). Epipophyses are present on NMMNH P-80484, which is a characteristic of Tanystropheidae. In spite of the limits posed by the preservation of the post-axial cervicals, the flattened ventral surface of the centrum, presence of epipophyses and hyperelongate axial centrum suggest that the Moenkopi cervicals are from a tanystropheid more closely related to Tanystropheus longobardicus. We do not know if there is one or multiple species of a Moenkopi Tanystropheus-like taxon, so we are hesitant to name the taxon.

\section{Axis}

The axis (DMNH 2018-05-0003) is identified by its inverted subtriangular anterior centrum surface in anterior view (Figure 2.5), as well as nonprojecting prezygapophyses (identification criteria from Nesbitt et al., 2015). The centrum has an anteroposterior length to dorsoventral height at centrum midpoint ratio of 4.02 . This value exceeds the approximate proportional length to height ratios of the axis in tanystropheids Macrocnemus bassanii (1.3), Amotosaurus rotfeldensis (2.8), and Dinocephalosaurus orientalis (2.2) (Fraser and Rieppel, 2006; Rieppel et al., 2008; Jaquier et al., 2017). This proportionally elongate axis relative to the axes in other taxa is similarly seen in the tanystropheids Tanytrachelos ahynis and Tanystropheus longobardicus (Olsen, 1979; Nosotti, 2007). In the Moenkopi form, there is a thin, shallow, ventral keel-like ridge present on the axis centrum which trends anteroposteriorly, and which is a very 

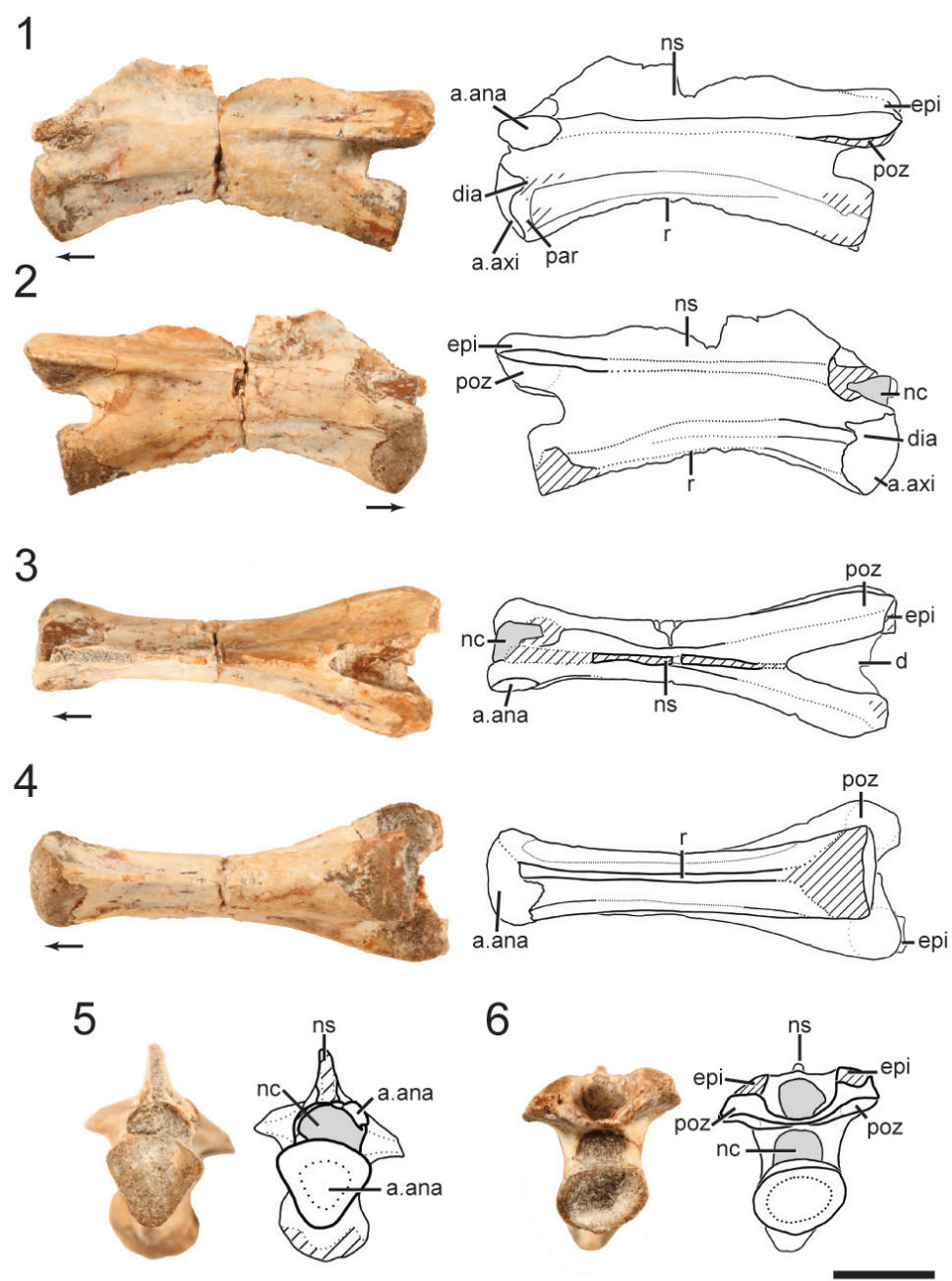

FIGURE 2. DMNH 2018-05-0003, axis of the Moenkopi tanystropheid, in 1, left lateral; $\mathbf{2}$, right lateral; 3, dorsal; 4, ventral; 5, anterior; and 6, posterior views. Arrows indicate anterior direction. Hatched areas indicate incomplete surface preservation and gray color indicates where matrix is exposed. Abbreviations: a., articulates with; ana, atlas neural arch; axi, axis intercentrum; dia, diapophysis; epi, epipophysis; nc, neural canal; poz, postzygapophysis; r. ridge. Scale bar equals $1 \mathrm{~cm}$.

widespread character state shared among diapsids and archosauromorphs and present in tanystropheids (Nesbitt et al., 2015; Ezcurra, 2016).

Epipophyses are present on the dorsal surface of the postzygapophyses but do not extend past their posterior edges, a character state shared with tanystropheids as well as other archosauromorphs like Azendohsaurus (Nesbitt et al., 2015). There are clear depressions on the anterolateral end of the centrum, ventral to the parapophyses and posterior to the lateral sides of the articular surface. An interzygapophyseal lamina connects the ventral portion of the bases of the zygapophyses at the midline, a feature also described in the post-axial cervical vertebrae from the Hayden
Quarry tanystropheid (Pritchard et al., 2015). The full anterior portion of the neural spine of the axis was originally preserved-as seen in Figure 3, a preliminary photograph of the specimen-although it was unfortunately broken and lost during handling, but was used to assess critical tanystropheid character states. The axial neural spine is anterodorsally expanded with an inclined dorsal margin (Nesbitt, 2011: character 244-state [1]; Nesbitt, 2015: character 179- state [1]; Ezcurra, 2016: character 329- state [1]). Though much of the posterior end of the axial neural spine is missing, it appears to have been dorsoventrally shorter than the centrum, a character state shared by the tanystropheids Tanystropheus longobardicus, Amotosaurus 


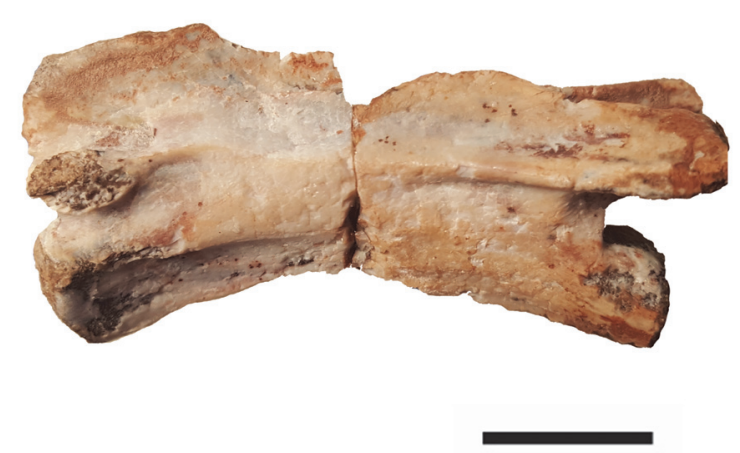

FIGURE 3. DMNH 2018-05-0003, axis of the Moenkopi tanystropheid with intact anterior portion of neural spine present. Scale bar equals $1 \mathrm{~cm}$.

rotfeldensis, and Macrocnemus bassanii (Ezcurra, 2016: character 328- state [1]). This dorsoventrally short neural spine and anterodorsal expansion are synapomorphies of Tanystropheidae in the analysis of Ezcurra (2016).

\section{Post-axial Cervical Vertebrae}

In the post-axial cervicals, only NMMNH P80482 (Figure 4) has the complete amphicoelous centrum preserved, but it is missing the majority of its neural arch including the neural spine. The centrum is highly elongate and greater than five times anteroposteriorly long than dorsoventrally tall. This extreme length-to-height ratio is a unique character state present in Tanystropheus longobardicus (Ezcurra, 2016: character 331- state [2]). In lateral view, the centrum is parallelogram-shaped, where the anterior portion is inclined about $15^{\circ}$ dorsal to the posterior portion. The centrum is waisted in ventral view and has the smallest proportional diameter at mid-length. The centrum articular surfaces are dorsoventrally compressed in the postaxial cervicals and deeply concave (Figures 4.5-6, $5.5,6.5)$. The centrum articular faces are ovalshaped in anterior and posterior views, with the long axis oriented transversely. A longitudinally oriented lamina extends the full length of the lateral centra posteriorly from the base of the parapophyses. This lamina results in a sharp change in slope between the ventral and lateral surfaces of the centrum which in anterior and posterior views is shown by the dorsoventral compression. This dorsoventral compression is shared in the tanystropheids Macrocnemus bassanii and Tanystropheus longobardicus and is a tanystropheid synapomorphy as determined by Ezcurra, 2016 (character 340- state [1]).
Although NMMNH P-80483 and P-80484 are partially preserved, being broken through the transverse plane near midpoint (Figures 5, 6), the centra are complete enough to discern the morphology of the centrum articular surfaces (anterior and posterior), parapophyses and diapophyses, and ventral surfaces. The morphology of these two specimens is nearly identical to that of NMMNH P-80482, but NMMNH P-80483 and P-80484 contain more anatomical information. The postaxial cervicals of the Moenkopi tanystropheid all have a flattened ventral surface lacking a ventromedial keel near the anterior and posterior ends, which is a character state shared by Tanystropheus longobardicus and Tanytrachelos ahynis (Dalla Vecchia, 2005). The cross section in the broken cervical vertebrae reveal a hollow core of the centrum of the cervicals, which was previously recognized in the cervicals of Tanystropheus longobardicus (Wild, 1973). In NMMNH P-80483, the neural canal is wider than tall (Figure 5.5), and the prezygapophyseal attachments overhang the canal slightly. In NMMNH P80482 the neural canal is flat ventrally and convex, forming a D-shape in cross-section (Figure 4.6).

Prezygapophyses and postzygapophyses are partially preserved in NMMNH P-80483 and NMMNH P-80484, respectively. There are epipophyses present on the postzygapophyses of NMMNH P-80484, though their posterior tips are broken (Figure 6). The presence of epipophyses on NMMNH P-80484 suggests that this cervical can be placed somewhere between the third to fifth cervical in the neck column constrained by comparisons with other members of Tanystropheidae (Ezcurra, 2016). Using NMMNH P-80482, we determine that the postzygapophyses are elevated dorsal to the prezygapophyses, which is a character seen in the geographically close Hayden Quarry tanystropheid fossils (Pritchard et al., 2015). Additionally, the dorsal border of the prezygapophyses is inclined approximately $45^{\circ}$ above the horizontal when viewed laterally (Figure 4.1-2). A shallow groove is present in NMMNH P-80483 on the lower lateral surface of the centrum that extends anteriorly along the represented centrum length (Figure 5.1-2).

All of the postaxial cervicals lack complete neural spines. In NMMNH P-80483 the dorsal margin of the neural spine is present anteriorly and indicates that the neural spine was dorsoventrally shorter than the dorsoventral height of the centrum. The broken surfaces of the neural spine in NMMNH P-80482 and NMMNH P-80484 (Figures $4.3,6.3)$ indicate that the neural spine extended 
1

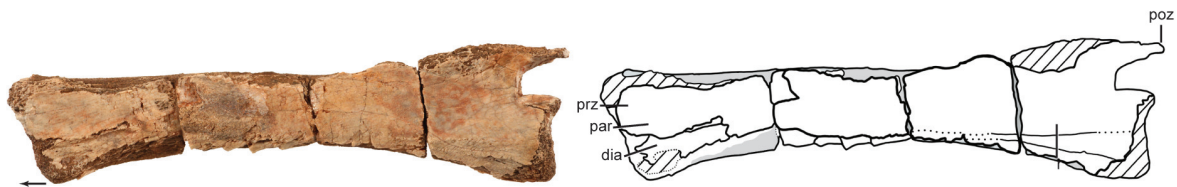

2
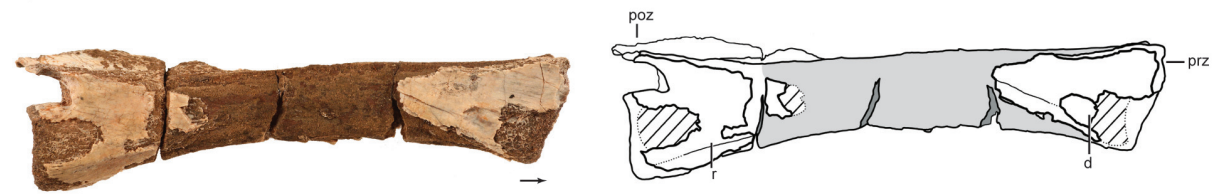

3
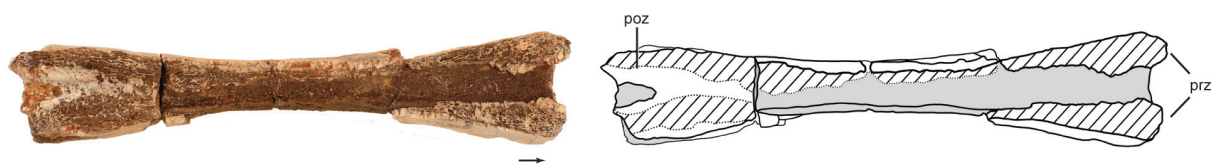

4
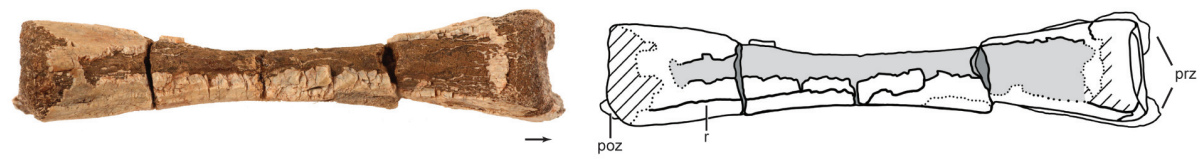

5

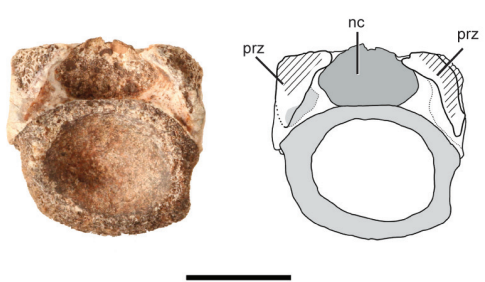

6

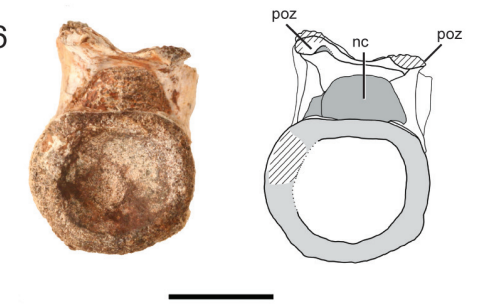

FIGURE 4. NMMNH P-80482, a post-axial cervical of the Moenkopi tanystropheid, in 1, left lateral; 2, right lateral; 3 , dorsal; 4, ventral; 5, anterior; and 6, posterior views. Arrows indicate anterior direction. Hatched areas indicate incomplete surface preservation and gray color indicates where matrix is exposed. Abbreviations: d, depression; dia, diapophysis; epi, epipophysis; nc, neural canal; par, parapophysis; poz, postzygapophysis; r, ridge. Scale bar equals 1 $\mathrm{cm}$.

the anteroposterior length of the neural arch, which is another consistent character state of tanystropheid cervicals (Ezcurra et al., 2014; Pritchard et al., 2015); anteroposteriorly long and dorsoventrally low cervical neural spines are present in the tanystropheids Amotosaurus rotfeldensis, Macrocnemus bassanii, Tanystropheus longobardicus, as well as non-tanystropheid archosauromorphs Protorosaurus speneri and Prolacerta broomi (Ezcurra, 2016: character 342 - state [1]). Because the neural spine is missing at the posterior end of NMMNH P-80484, and entirely in NMMNH P80482, we cannot estimate the full anteroposterior extent of the neural spines in the postaxial cervicals.

The complete cervical, NMMNH P-80482, has an estimated ratio of centrum length versus height at the anterior margin of 6.20. This falls in the range of $6.09-6.80$ as a synapomorphy for the tanystropheids Amotosaurus rotfeldensis and Tanystropheus longobardicus and also suggests that NMMNH P-80482 is the fourth or fifth cervical as based on Tanystropheus longobardicus (Ezcurra, 2016: character 331- state [2]). In measuring these cervical vertebrae, we did not take into account compression. However, these cervical vertebrae are minimally crushed and even if they were up to $15 \%$ off, they would still fall in the synapomorphic range of length to height ratio for Tanystropheus and Amotosaurus. Additionally, tanystropheids, which lack hyperelongate neck proportions have a length to height ratio in the range of 2.92-4.12 for their fourth and fifth cervicals, well below the measured range of our Moenkopi tanystropheid cervical vertebrae (Ezcurra, 2016: character 331-state [1]). We reconstructed estimated full centrum lengths of NMMNH P-80483 and NMMNH P-80484, based on centrum propor- 

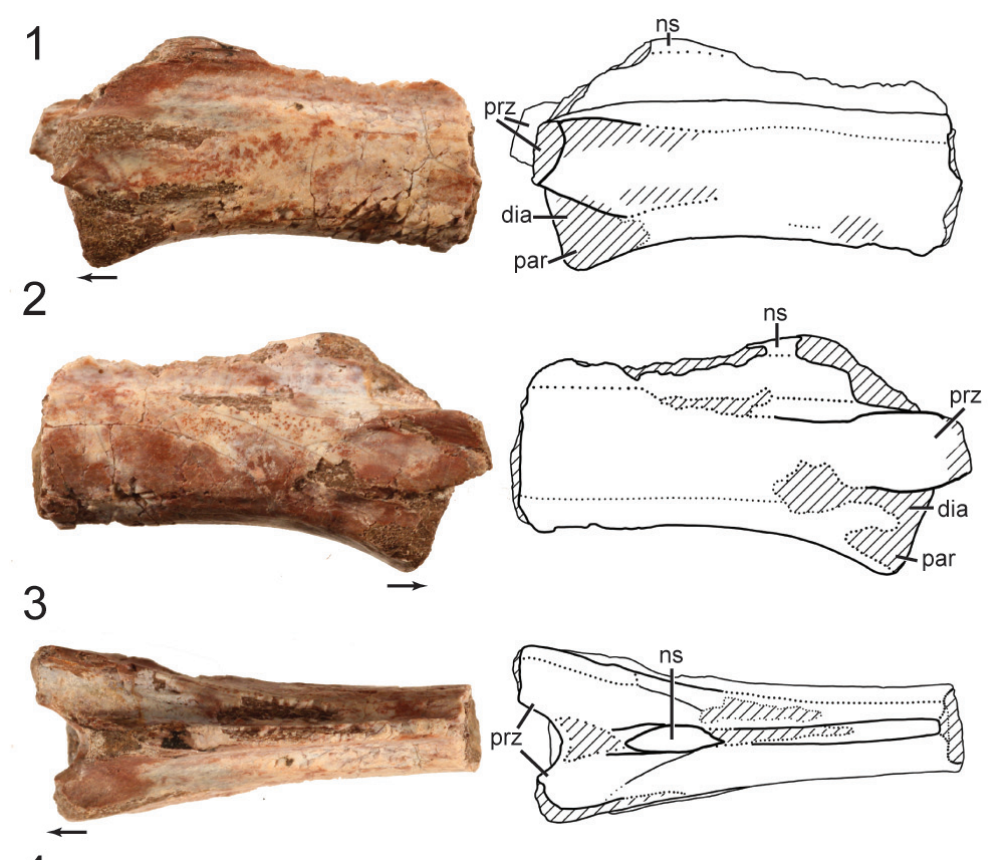

4
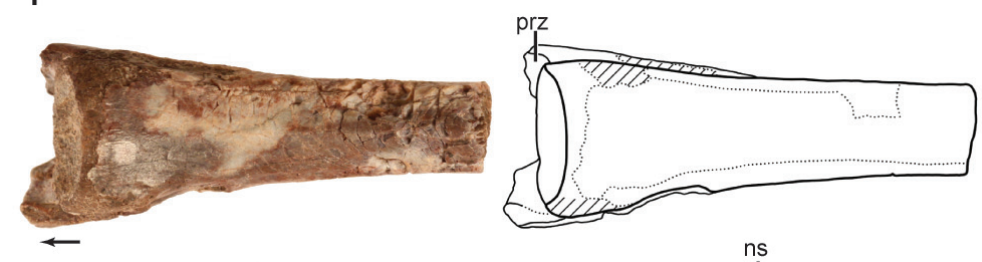

5
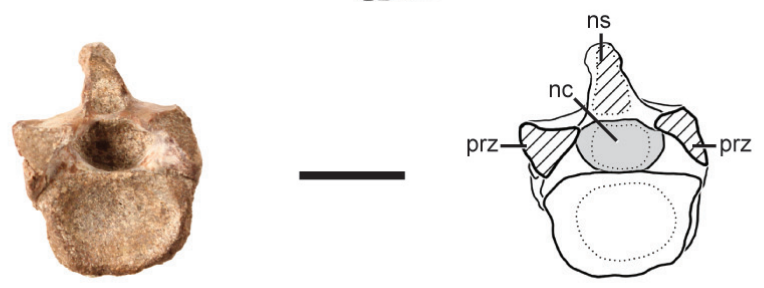

FIGURE 5. NMMNH P-80483, a post-axial cervical of the Moenkopi tanystropheid, in 1, left lateral; 2, right lateral; 3, dorsal; 4, ventral; and 5, anterior views. Arrows indicate anterior direction. Hatched areas indicate incomplete surface preservation and gray color indicates where matrix is exposed. Abbreviations: dia, diapophysis; nc, neural canal; ns, neural spine; par, parapophysis; prz, prezygapophysis. Scale bar equals $1 \mathrm{~cm}$.

tions in NMMNH P-80482 (Table 1). The extremely elongate cervicals are indicative of an elongated neck, though this is also dependent on the number of cervicals. Tanystropheus longobardicus has 13, and Amotosaurus rotfeldensis has eight (Wild, 1973; Fraser and Rieppel, 2006). As further comparison, Dinocephalosaurus orientalis, a possible tanystropheid, has at least 27 cervicals ( $\mathrm{Li}$ et al., 2004; Rieppel et al., 2008). It is unknown at this time how many total cervicals were present in the Moenkopi tanystropheid, but the general morphology of the individual cervicals is Tanystropheus-like potentially alluding to a similar number of cervicals for the Moenkopi form and similar hyperelongate neck proportions.

\section{DISCUSSION}

\section{Size Estimation}

In terms of body size, Tanystropheus longobardicus is by far the largest-known tanystropheid at an estimated $6 \mathrm{~m}$ total body length (Wild, 1973; Nosotti, 2007). Our methodology for estimating the snout-vent length is based on the axis (DMNH 2018-05-0003). We used Tanystropheus longobardicus as our proxy for estimating the total length of 

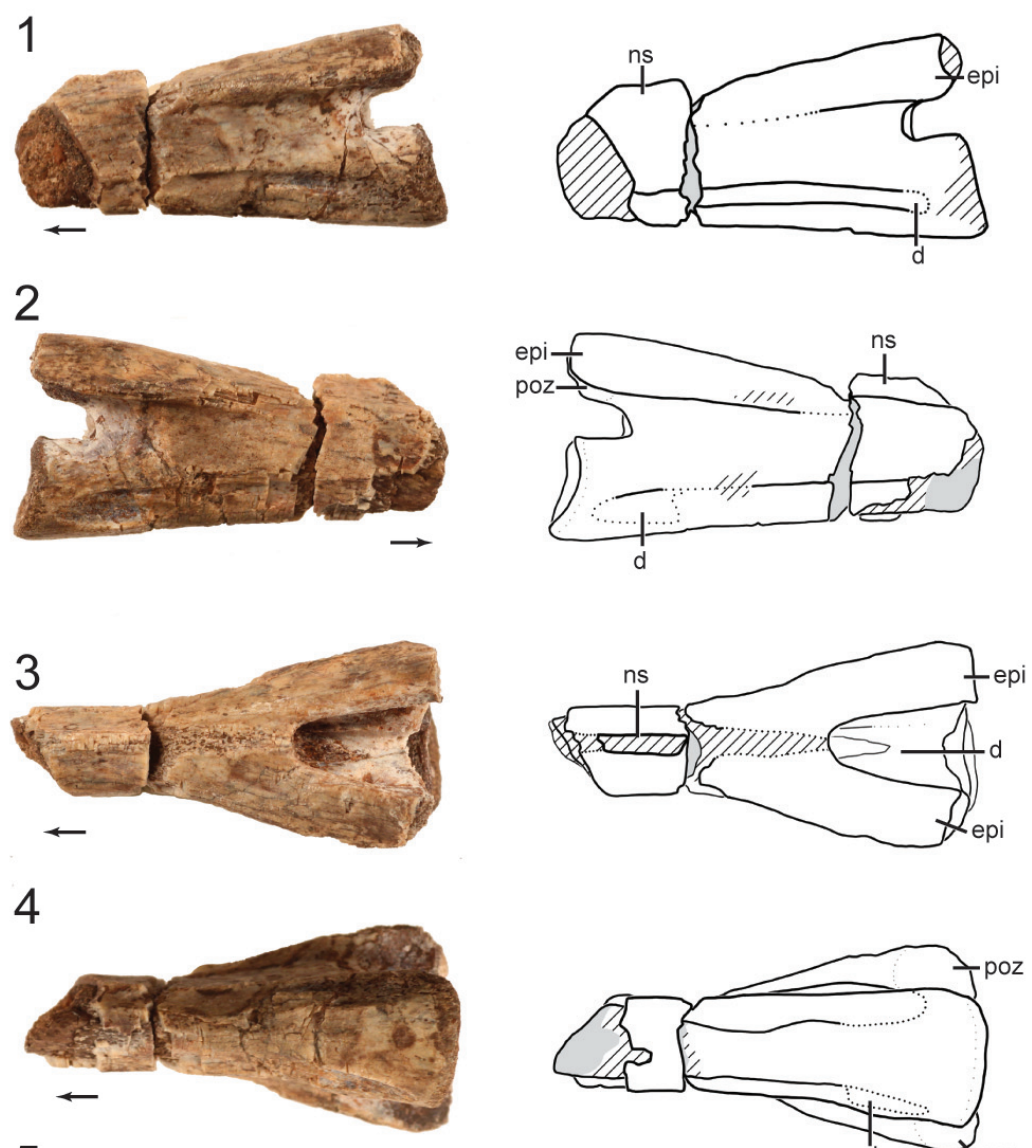

5
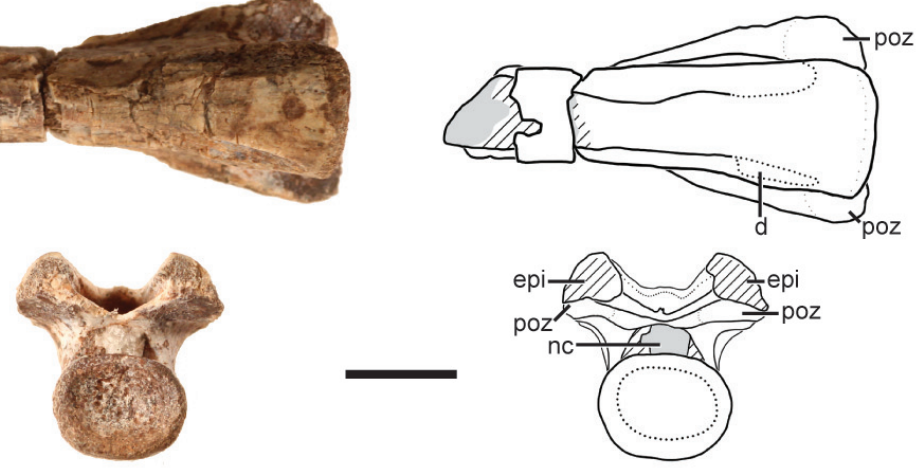

FIGURE 6. NMMNH P-80484, a post-axial cervical of the Moenkopi tanystropheid, in 1, left lateral; 2, right lateral; 3, dorsal; 4, ventral; and 5, posterior views. Arrows indicate anterior direction. Hatched areas indicate incomplete surface preservation and gray color indicates where matrix is exposed. Abbreviations: d, depression; epi, epipophysis; nc, neural canal; ns, neural spine; poz, postzygapophysis; prz, prezygapophysis. Scale bar equals $1 \mathrm{~cm}$.

the Moenkopi form because other tanystropheids with similarly complete skeletons (Macrocnemus bassanii, Amotosaurus rotfeldensis,

Langobardisaurus pandolfii, and Tanytrachelos ahynis) do not bear the amphicoelous, hyperelongated, straight cervical vertebrae seen in Tanystropheus longobardicus or the Moenkopi form. They also lack an axis with such a relatively elongate centrum. These characters can be seen in PIMUZ T2791 and MCSN BES SC 265, which are the most complete skeletons of Tanystropheus that preserve skulls and nearly complete presacral vertebral columns. Therefore, the major assumption in this size estimate is that the Moenkopi tanystropheid is similar in proportion to Tanystropheus longobardicus as based on the referred cervical vertebrae.

We used the measurements of various vertebrae from Wild (1973) and Nosotti (2007) and then imported images of the complete skeletons into ImageJ. We used the known lengths of the second cervical vertebra to set the scale for the images and then measured the length of the skull and entire presacral vertebral column. We added those measurements together to estimate the total snoutvent length, then took the ratio of the snout-vent length (SV) to the total centrum length of the axis. In both specimens, the SVIAxis ratio comes out at 
TABLE 1. Measurements of Moenkopi tanystropheid cervical vertebrae. N/A indicates this portion was unable to be determined with the represented material, and " $e$ " indicates estimated length value.

\begin{tabular}{lcccc}
\hline Referred specimen & $\begin{array}{c}\text { Anterior centrum } \\
\text { end height } \\
(\mathbf{m m})\end{array}$ & $\begin{array}{c}\text { Posterior centrum } \\
\text { end height } \\
\mathbf{( m m}\end{array}$ & $\begin{array}{c}\text { Mid-centrum } \\
\text { height } \\
(\mathbf{m m})\end{array}$ & $\begin{array}{c}\text { Full centrum } \\
\text { length } \\
(\mathbf{m m})\end{array}$ \\
\hline DMNH 201805-0003 & 9.11 & 6.41 & 6.49 & 36.63 \\
NMMNH P-80482 & 13.50 & 13.67 & 12.15 & 83.72 \\
NMMNH P-80483 & 10.28 & N/A & N/A & $63.73 \mathrm{e}$ \\
NMMNH P-80484 & N/A & 9.37 & N/A & $57.44 \mathrm{e}$ \\
\hline
\end{tabular}

approximately 60 . Therefore, we estimate that the snout-vent length of the Moenkopi tanystropheid is equivalent to 60 times the length of the preserved axis, which is approximately $2.20 \mathrm{~m}$, at maximum, based on the axial centrum length of $36.63 \mathrm{~mm}$ as shown in Table 1.

The Moenkopi tanystropheid cervical vertebrae belong to a considerably smaller tanystropheid than the largest Tanystropheus, but we determined that its body length was approximately three times larger than Tanytrachelos ahynis known primarily from the eastern United States (Olsen, 1979; Casey et al. 2007). Additionally, the full length cervical, NMMNH P-80482, is approximately three times longer than the cervical vertebrae of the geographically-close Hayden Quarry tanystropheid of New Mexico (Pritchard et al., 2015). Therefore, the Moenkopi tanystropheid cervical vertebrae correspond to both a larger tanystropheid and more Tanystropheus-like taxon compared to other biogeographically close tanystropheids.

\section{Large-bodied, Hyperelongate-necked Tanystropheids in Western Pangaea}

The Moenkopi tanystropheid cervicals belong to one of the larger known members of the clade found in western Pangaea. The lengths of these cervicals and body size estimation are indicative of an animal that was approximately three times larger than Tanytrachelos ahynis and the Hayden Quarry tanystropheid (Olsen, 1979; Casey et al. 2007; Pritchard et al., 2015). As suggested by the proportionally extreme centrum elongation of the referred cervical vertebrae, a synapomorphic character for Tanystropheus, the western Pangaean Moenkopi tanystropheid is likely closely related to the eastern Pangaean Tanystropheus longobardicus, which possessed some of the most extreme neck proportions of any animal (Wild, 1973; Fraser and Rieppel, 2006).

The recognition of the Moenkopi tanystropheid and its relationship to Tanystropheus has implications for tanystropheid paleobiogeography and ecology. First, the Moenkopi form adds to recent western North American tanystropheid discoveries further bolstering the large biogeographic range for tanystropheidae and their western Pangaean radiation. The Moenkopi tanystropheid additionally reveals a disparity in the morphologies of tanystropheids in western North America, a region where the associated tanystropheids lacked the hyperelongated neck and larger body size present in Tanystropheus-like taxa.

Tanystropheus is primarily known from central and eastern Pangaea of what is now Eurasia in mid to higher latitudes and associated with the Tethys coastal regions (Wild, 1873; Nosotti, 2007; Rieppel et al., 2010; Sennikov, 2011). The Moenkopi form places tanystropheids with the same body plan as Tanystropheus as occurring on the other side of the world at the same temporal range, the Middle Triassic. Therefore, the Moenkopi tanystropheid greatly extends the concurrent biogeographic range of the Tanystropheus-like taxa (Figure 7). However, these cervicals were recovered in sediments that had little to no marine influence and corresponded to an equatorial latitude. Other non-marine fauna found in these members of the Moenkopi Formation include terrestrial archosaurs and dicynodonts (Morales, 1987; Hunt et al.,1993; Nesbitt, 2003; 2005). A continental, fluvial setting is a unique environment to find hyperelongate-necked Tanystropheus-like tanystropheids, which are typically associated with marginal marine environments. Tanystropheus-like tanystropheids were a morphologically unique archosauromorph clade, and these new fluvial finds pose interesting questions about the ecology of these hyperelongate-necked tanystropheids. Were they filling different ecological roles across marginal marine to terrestrial fluvial environments, or were they filling similar ecological roles in these disparate environments? Further studies and considerations of Tanystropheus ecology should incorporate the Moenkopi tanystropheid fossils. 


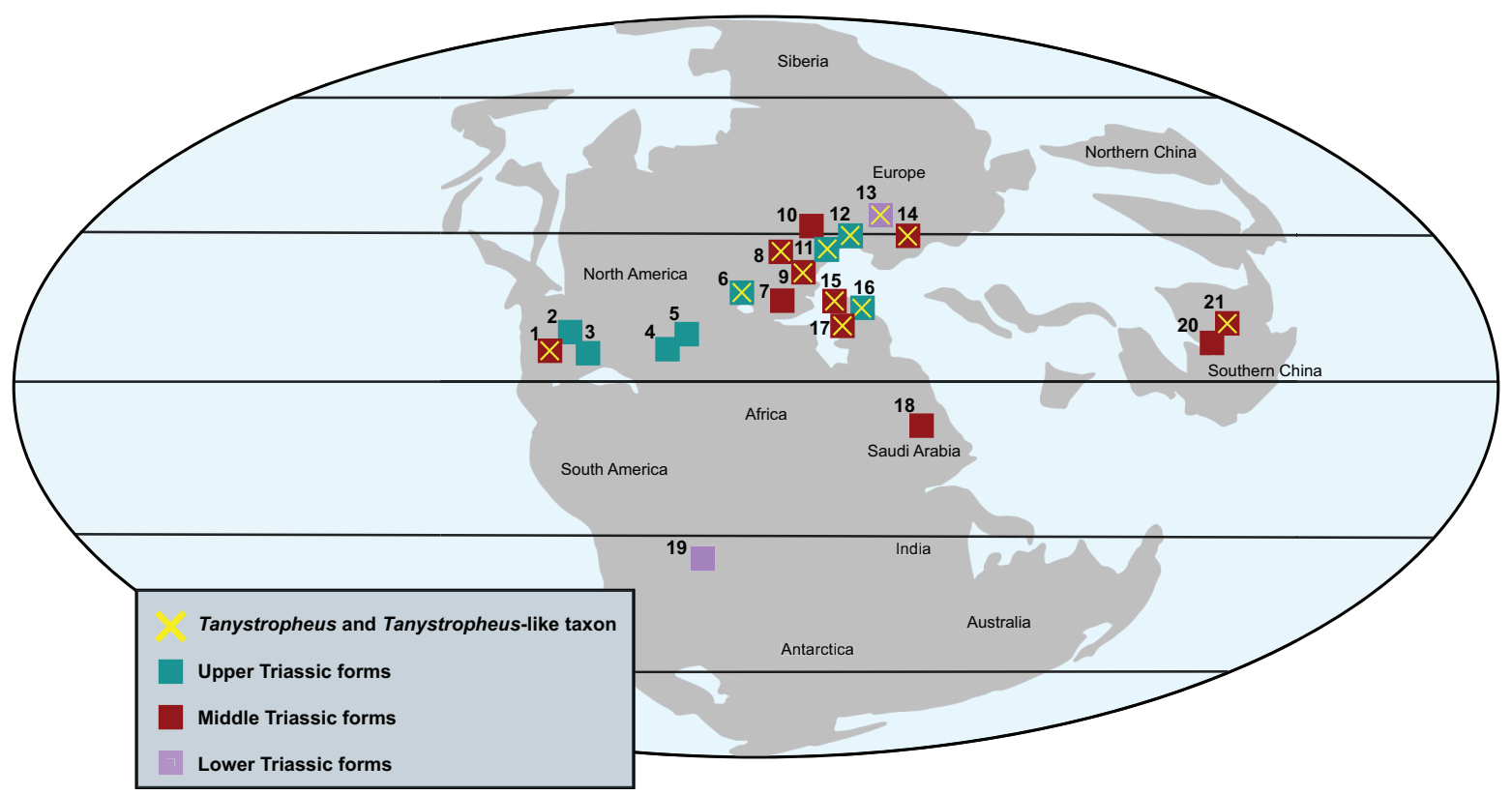

FIGURE 7. Occurrences of the family Tanystropheidae in Triassic Pangaea as indicated by squares. 1. Moenkopi Formation, Arizona and New Mexico; 2. Chinle Formation, New Mexico; 3. Cooper Canyon Formation, Texas; 4. Cow Branch Formation, Virginia; 5. Lockatong Formation, Newark Supergroup, New Jersey and Pennsylvania; 6 . Wolfville Formation, Nova Scotia; 7. Montral-Alcover Basin, Spain; 8. Otter Sandstone Formation, England; 9. Limestone Alps and Valle Serrata Locality, Switzerland; 10. Quarry Kossig, Upper Buntsandstein of the Black Forest, Germany 11. Bayreuth localities, Germanic Basin, Germany; 12. Seefeld Formation, Austria; 13. Don River Basin, Lipovskaya Formation, Eastern Europe 14. Bihor Mountain Localities, Romania; 15. Calcare di Zorzino, Italy; 16. Dolomia di Forni, Italy; 17. Besano Formation, Italy; 18. Jilh Formation, Saudi Arabia; 19. Sanga do Cabral Formation, Brazil; 20, 21. Zhuganpo Member of the Falang Formation, China. (Bassani, 1886; Wild, 1973, 1980b; Jurcsak, 1975; Milner et al., 1990; Muscio, 1996; Vickers-Rich et al., 1999; Sues, 2003; Rieppel, 2004; Fraser, 2006; Renesto, 2006; Casey et al., 2007; Borsuk-Białynicka and Evans, 2009; Rieppel et al., 2010; Sennikov, 2011; Diedrich, 2012; Saller et al., 2013; Pritchard et al., 2015; Jaquier et al., 2017; De Oliviera et al., 2018; Lessner et al., 2018.)

Tanystropheus-like tanystropheids, as a clade, seem to have occupied similar, but broad ranging semi-aquatic environments during their 35 million year span in the Triassic Period. The biogeographic and environmental factors of these Moenkopi tanystropheids further refute the marine, water-restricted ecomorphological hypothesis for hyperelongate necked tanystropheids. In the past, there were preconceived limitations conferred by the extreme morphology in Tanystropheus-like tanystropheids and it was thought that only a full aquatic lifestyle could support their bizarre neck morphology (Tschanz, 1988; Rieppel, 1989; Nosotti, 2007). Recent studies, however, have placed Tanystropheus on the shoreline with specifically semi-aquatic adaptations including swimming via symmetrical strokes of the hind limbs and rowing through the water (Renesto and Saller, 2018), as well as bone histology analyzing femur density of Tanystropheus, which suggests an amphibious lifestyle (Jaquier and Scheyer 2017). Additionally, Beardmore and Furrer (2018) used taphonomy to infer a terrestrial or at least near-shore, shallow marine origin for preserved Tanystropheus carcasses (Beardmore and Furrer, 2018). The recovery of the Moenkopi tanystropheid in fluvial sediments further supports the semi-aquatic, shore dwelling ecology of Tanystropheus-like tanystropheids, which lacked full adaptations for continuous swimming; however, it also demonstrates that Tanystropheus-like taxa could occupy more than just marine shores. Recognition of these new Moenkopi fossils suggests that these highly derived tanystropheids were able to occupy a range of aquatic environments, both marine and continental freshwater, and that there were aspects of their life history which required close proximity to water. 


\section{ACKNOWLEDGEMENTS}

We thank E. Lessner for collection of these specimens, S.G. Lucas and N. Ridgewell for curation, the New Mexico Museum of Natural History and Science, the Perot Museum of Nature and Science, as well as private landowners for land access to the outcrops. This project was funded by the Virginia Tech Department of Geosciences and is supported by the National Science Foundation Graduate Research Fellowship Program, grant number DGE-1418060. Additional thanks to the Jackson School of Geosciences Student Travel Grant which allowed these findings to be presented at the Society of Vertebrate Paleontology's $77^{\text {th }}$ Annual Meeting. This work is Petrified Forest National Park Paleontological Contribution No. 68. The views expressed herein are those of the authors and do not represent the opinions of the United States Government.

\section{REFERENCES}

Bassani, F. 1886. Sui fossili e sull'eta degli schisti bituminosi triasici di Besano in Lombardia. Atti Società Italiana di Scienze Naturali, 29:15-72.

Beardmore, S.R. and Furrer, H. 2018. Land or water: using taphonomic models to determine the lifestyle of the Triassic protorosaur Tanystropheus (Diapsida, Archosauromorpha). Palaeobiodiversity and Palaeoenvironments, 98:243-258. https://doi.org/10.1007/s12549017-0299-7

Benton, M.J. 1985. Classification and phylogeny of the diapsid reptiles. Zoological Journal of the Linnaean Society, 84:97-164. https://doi.org/10.1111/j.1096-3642.1985.tb01796.x

Borsuk-Białynicka, M. and Evans, S.E. 2009. A long-necked archosauromorph from the Early Triassic of Poland. Palaeontologia Polonica, 65:203-234.

Casey, M.M., Fraser, N.C., and Kowalewski, M. 2007. Quantitative taphonomy of a Triassic reptile Tanytrachelos ahynis from the Cow Branch Formation, Dan River Basin, Solite Quarry, Virginia. Palaios, 22:598-611. https://doi.org/10.2110/palo.2006.p06-010r

Dalla Vecchia, F.M. 2000. Tanystropheus (Archosauromorpha, Prolacertiformes) remains from the Triassic of the northern Friuli (NE Italy). Rivista Italiana di Paleontologia e Stratigrafia, 106:135-140. https://doi.org/10.13130/2039-4942/5394

De Oliveira, T.M., Oliveira, D., Schultz, C.L., Kerber, L., and Pinheiro. F.L. 2018. Tanystropheid archosauromorphs in the Lower Triassic of Gondwana. Acta Palaeontologica Polonica, 63:713-723. https://doi.org/10.4202/app.00489.2018

Diedrich, C. 2012. The Middle Triassic marine reptile biodiversity in the Germanic Basin, in the centre of the Pangaean world. Open Geosciences, 4:9-46. https://doi.org/10.2478/s13533011-0060-0

Dilkes, D.W. 1998. The Early Triassic rhynchosaur Mesosuchus browni and the interrelationships of basal archosauromorph reptiles. Philosophical Transactions of the Royal Society of London B: Biological Sciences, 353:501-541. https://doi.org/10.1098/ rstb.1998.0225

Ezcurra, M.D. 2016. The phylogenetic relationships of basal archosauromorphs, with an emphasis on the systematics of proterosuchian archosauriforms. PeerJ, 4:e1778. https:// doi.org/10.7717/peerj.1778

Ezcurra, M.D., Scheyer, T.M., and Butler, R.J. 2014. The origin and early evolution of Sauria: reassessing the Permian saurian fossil record and the timing of the crocodile-lizard divergence. PLoS ONE, 9:e89165. https://doi.org/10.1371/journal.pone.0089165

Ezcurra, M.D. and Butler, R.J. 2018. The rise of the ruling reptiles and ecosystem recovery from the Permo-Triassic mass extinction. Proceedings of the Royal Society B, 285:20180361. https://doi.org/10.1098/rspb.2018.0361

Foth, C., Ezcurra, M.D., Sookias, R.B., Brusatte, S.L., and Butler, R.J. 2016. Unappreciated diversification of stem archosaurs during the Middle Triassic predated the dominance of dinosaurs. BMC Evolutionary Biology, 16:188. https://doi.org/10.1186/s12862-016-0761-6

Fraser, N.C., Grimaldi, D.A., Olsen, P.E., and Axsmith, B. 1996. A Triassic Lagerstätte from eastern North America. Nature, 380:615-619. https://doi.org/10.1038/380615a0 
Fraser, N.C. and Rieppel, O. 2006. A new protorosaur (Diapsida) from the Upper Buntsandstein of the Black Forest, Germany. Journal of Vertebrate Paleontology, 26:866-871. https:// doi.org/10.1671/0272-4634(2006)26[866:anpdft]2.0.co;2

Gervais, P. 1859. Zoologie et Paleontologie Francaises, Second Edition. Bertrand, Paris.

Gregory, J.T. 1945. Osteology and relationships of Trilophosaurus. University of Texas Publications, 4401:273-359.

Huene, F.V. 1946. Die grossen Stämme der Tetrapoden in den geologischen Zeiten. Biologisches Zentralblatt, 65:268-275.

Hunt, A.P., Santucci, V.L., Lockley, M.G., and Olson, T.J. 1993. Dicynodont trackways from the Holbrook Member of the Moenkopi Formation (Middle Triassic: Anisian), Arizona, USA. New Mexico Museum of Natural History and Science Bulletin, 3:213-218.

Jaquier, V.P. and Scheyer, T.M. 2017. Bone histology of the Middle Triassic long-necked reptiles Tanystropheus and Macrocnemus (Archosauromorpha, Protorosauria). Journal of Vertebrate Paleontology, 37:e1296456. https://doi.org/10.1080/02724634.2017.1296456

Jaquier, V.P., Fraser, N.C., Furrer, H., and Scheyer, T.M. 2017. Osteology of a new specimen of Macrocnemus aff. M. fuyuanensis (Archosauromorpha, Protorosauria) from the Middle Triassic of Europe: potential implications for species recognition and paleogeography of tanystropheid protorosaurs. Frontiers in Earth Science, 5:91. https://doi.org/10.3389/ feart.2017.00091

Jiang, D.-Y., Rieppel, O., Fraser, N.C., Motani, R., Hao, W.-C., Tintori, A., Sun, Y.-L., and Sun, Z.Y. 2011. New information on the protorosaurian reptile Macrocnemus fuyuanensis from the Middle/Upper Triassic of Yunnan, China. Journal of Vertebrate Paleontology, 31:1230-1237. https://doi.org/10.1080/02724634.2011.610853

Jurcsak, T. 1975. Tanystropheus biharicus n.sp. (Reptilia, Squamata), o nouva specie pentru fauna Triasica a României. Nymphaea, 3:45-52.

Lessner, E.J., Parker, W.G., Marsh, A.D., Nesbitt, S.J., Irmis, R.B., and Mueller, B.D. 2018. New insights into Late Triassic dinosauromorph-bearing assemblages from Texas using apomorphy-based identifications. PaleoBios, 35:1-45.

Li, C., Rieppel, O., and LaBarbera, M.C. 2004. A Triassic aquatic protorosaur with an extremely long neck. Science, 305:1931-1931. https://doi.org/10.1126/science.1100498

Li, C., Rieppel, O., Wu, X.-C., Zhao, L.-J., and Wang, L.-T. 2011. A new Triassic marine reptile from southwestern China. Journal of Vertebrate Paleontology, 31:303-312. https://doi.org/ 10.1080/02724634.2011.550368

Li, C., Zhao, L.J., and Wang, L.T. 2007. A new species of Macrocnemus (Reptilia: Protorosauria) from the Middle Triassic of southwestern China and its palaeogeographical implication. Science in China, Series D (Earth Sciences), 50:1601-1605. https://doi.org/10.1007/s11430007-0118-5

Lucas, S.G. and Hunt, A.P. 1987. Stratigraphy of the Anton Chico and Santa Rosa Formations, Triassic of East-Central New Mexico. Journal of the Arizona-Nevada Academy of Science, 22:21-33

Lucas, S.G. and Schoch, R.R. 2002. Triassic temnospondyl biostratigraphy, biochronology and correlation of the German Buntsandstein and North American Moenkopi Formation. Lethaia, 35:97-106. https://doi.org/10.1111/j.1502-3931.2002.tb00071.x

McCartney, J. 1802. Preface and Table III; in G. Cuvier, Lectures on Comparative Anatomy. Translated by W. Ross. Oriental Press, Wilson and Co., for T. N. Longman and O. Rees, Paternoster Row, London. https://doi.org/10.4159/harvard.9780674283701.c5

McKee, E.D. 1954. Stratigraphy and history of the Moenkopi Formation of Triassic age. Geological Society of America Memoirs, 61:1-126. https://doi.org/10.1130/mem61-p1

Milner, A.R., Gardiner, B.G., Fraser, N.C., and Taylor, M.A. 1990. Vertebrates from the Middle Triassic Otter Sandstone Formation of Devon. Palaeontology, 33:873-892.

Morales, M. 1987. Terrestrial fauna and flora from the Triassic Moenkopi Formation of the southwestern United States. Journal of the Arizona-Nevada Academy of Science, 22(1):1-19.

Nesbitt, S.J. 2011. The early evolution of archosaurs: relationships and the origin of major clades. Bulletin of the American Museum of Natural History, 352:1-292. https://doi.org/ $10.1206 / 352.1$ 
Nesbitt, S.J., Flynn J.J., Pritchard, A.C., Parrish, J.M., Ranivoharimanana, L., and Wyss, A.R. 2015. Postcranial osteology of Azendohsaurus madagaskarensis (?Middle to Upper Triassic, Isalo Group, Madagascar) and its systematic position among stem archosaur reptiles. Bulletin of the American Museum of Natural History, 398:1-126. https://doi.org/10.1206/ amnb-899-00-1-126.1

Nesbitt, S.J., Lucas, S.G., and Schoch, R.R. 2006. A new, large archosauriform from the Anton Chico Member of the upper Moenkopi Formation (Middle Triassic), east-central New Mexico, USA. Neues Jahrbuch für Geologie und Paläontologie, Abhandlungen, 239:289-311.

Nosotti, S. 2007. Tanystropheus longobardicus (Reptilia, Protorosauria): reinterpretations of the anatomy based on new specimens from the Middle Triassic of Besano (Lombardy, northern Italy). Memorie della Società Italiana di Scienze Naturali e del Museo Civico di Storia Naturale di Milano, 35:1-88.

Olsen, P. E. 1979. A new aquatic eosuchian from the Newark Supergroup (Late Triassic-Early Jurassic) of North Carolina and Virginia. Postilla, 176:1-14.

Osborn, H. F. 1903. Ornitholestes hermanni, a new compsognathoid dinosaur from the Upper Jurassic. Bulletin of the American Museum of Natural History, 19:459-464.

Pritchard, A.C., Turner, A.H., Nesbitt, S.J., Irmis, R.B., and Smith, N.D. 2015. Late Triassic tanystropheids (Reptilia, Archosauromorpha) from northern New Mexico (Petrified Forest Member, Chinle Formation) and the biogeography, functional morphology, and evolution of Tanystropheidae. Journal of Vertebrate Paleontology, 35:e911186. https://doi.org/10.1080/ 02724634.2014 .911186

Pritchard, A.C. and Nesbitt, S.J. 2017. A bird-like skull in a Triassic diapsid reptile increases heterogeneity of the morphological and phylogenetic radiation of Diapsida. Royal Society Open Science, 4:170499. https://doi.org/10.1098/rsos.170499

Reisz, R.R. and Müller, J. 2004. Molecular timescales and the fossil record: A paleontological perspective. Trends in Genetics, 20:237-241. https://doi.org/10.1016/s0168-9525(04)000757

Renesto, S. 1994. A new prolacertiform reptile from the Late Triassic of northern Italy. Rivista Italiana di Paleontologia e Stratigrafia, 100:285-306. https://doi.org/10.13130/2039-4942/ 8615

Renesto, S. 2005. A new specimen of Tanystropheus (Reptilia Protorosauria) from the Middle Triassic of Switzerland and the ecology of the genus. Rivista Italiana di Paleontologia e Stratigrafia, 111:2039-4942. https://doi.org/10.13130/2039-4942/6327.

Renesto, S. 2006. A reappraisal of the diversity and biogeographic significance of the Norian (Late Triassic) reptiles from the Calcare di Zorzino. New Mexico Museum of Natural History and Science Bulletin, 37:445-456.

Renesto S. and Dalla Vecchia, F.M. 2000. The unusual dentition and feeding habits of the prolacertiform reptile Langobardisaurus (Late Triassic, Northern Italy). Journal of Vertebrate Paleontology, 20:622-627. https://doi.org/10.1671/02724634(2000)020[0622:TUDAFH]2.0.CO;2

Renesto, S. and Saller, F. 2018. Evidences for a semi aquatic life style in the Triassic diapsid reptile Tanystropheus. Rivista Italiana di Paleontologia e Stratigrafia, 124:23-24. https:// doi.org/10.13130/2039-4942/9541

Rieppel, O., Jiang, D.-Y., Fraser, N.C., Hao, W.-C., Motani, R., Sun, Y.-L., and Sun, Z.-Y. 2010. Tanystropheus cf. T. longobardicus from the early Late Triassic of Guizhou Province, southwestern China. Journal of Vertebrate Paleontology, 30:1082-1089. https://doi.org/ 10.1080/02724634.2010.483548

Rieppel, O., Li, C., and Fraser, N.C. 2008. The skeletal anatomy of the Triassic protorosaur Dinocephalosaurus orientalis $\mathrm{Li}$, from the Middle Triassic of Guizhou Province, southern China. Journal of Vertebrate Paleontology, 28:95-110. https://doi.org/10.1671/02724634(2008)28[95:tsaott]2.0.co;2

Romer, A.S. 1956. The Osteology of the Reptilia. University of Chicago Press, Chicago.

Sahney, S. and Benton, M.J. 2008. Recovery from the most profound mass extinction of all time. Proceedings of the Royal Society B, 275:759-765. https://doi.org/10.1098/rspb.2007.1370

Saller, F., Renesto S., and Dalla Vecchia, F.M. 2013. First record of Langobardisaurus (Diapsida, Protorosauria) from the Norian (Late Triassic) of Austria, and a revision of the genus. Neues Jahrbuch Geologie Paläontologie Abhandlugen, 268:83-95. https://doi.org/10.1127/0077$7749 / 2013 / 0319$ 
Sanz, J.L. and López-Martínez, N. 1984. The prolacertid lepidosaurian Cosesaurus aviceps Ellenberger and Villalta, a claimed «Protoavian» from the Middle Triassic of Spain. Geobios, 17:747-755. https://doi.org/10.1016/s0016-6995(84)80119-9

Sennikov, A.G. 2011. New tanystropheids (Reptilia: Archosauromorpha) from the Triassic of Europe. Paleontological Journal, 45:90-104. https://doi.org/10.1134/s0031030111010151

Sues, H.-D. 2003. An unusual new archosauromorph reptile from the Upper Triassic Wolfville Formation of Nova Scotia. Canadian Journal of Earth Sciences, 40:635-649. https://doi.org/ 10.1139/e02-048

Sues, H.-D. and Fraser, N.C. 2010. Triassic Life on Land. Columbia University Press, New York.

Tschanz, K. 1988. Allometry and heterochrony in the growth of the neck of Triassic prolacertiform reptiles. Palaeontology, 31:997-1011.

Vickers-Rich, P., Rich, T.H., Rieppel, O., Thulborn, R.A., and McClure, H.A. 1999. A Middle Triassic vertebrate fauna from the Jihl Formation, Saudi Arabia. Neues Jahrbuch für Geologie und Palaontologie, Abhandlungen, 213:201-232. https://doi.org/10.1127/njgpa/213/ 1999/201

Wild, R. 1980. Die Triasfauna der Tessiner Kalkalpen. XXIV. Neue funde von Tanystropheus (Reptilia, Squamata). Schweizerische Paläontologische Abhandlungen, 102:1-43.

Wild, R. 1973. Die Triasfauna der Tessiner Kalkalpen. XXIII. Tanystropheus longobardicus (Bassani) (Neue Ergebnisse). Abhandlungen der Schweizerischen Paläontologischen Gesellschaft, 95:1. 